\title{
A Double-Edged Sword-Cardiovascular Concerns of Potential Anti-COVID-19 Drugs
}

\author{
Wen-Liang $\mathrm{Yu}^{1,2} \cdot$ Han Siong Toh ${ }^{1,3} \cdot$ Chia-Te Liao ${ }^{4,5} \cdot$ Wei-Ting Chang ${ }^{3,4,6}$ \\ Accepted: 8 June 2020 / Published online: 17 June 2020 \\ (C) Springer Science+Business Media, LLC, part of Springer Nature 2020
}

\begin{abstract}
Coronavirus disease 2019 (COVID-19) is a pandemic infection caused by Severe Acute Respiratory Syndrome Coronavirus 2 (SARS-CoV-2). COVID-19 significantly affects multiple systems including the cardiovascular system. Most importantly, in addition to the direct injury from the virus per se, the subsequent cytokine storm, an overproduction of immune cells and their activating compounds, causes devastating damage. To date, emerging anti-SARS-CoV-2 treatments are warranted to control epidemics. Several candidate drugs have been screened and are currently under investigation. These primarily include antiviral regimens and immunomodulatory regimens. However, beyond the anti-SARS-CoV-2 effects, these drugs may also have risks to the cardiovascular system, especially altering cardiac conduction. Herein, we review the cardiovascular risks of potential antiCOVID-19 drugs.
\end{abstract}

Keywords COVID-19 $\cdot$ SARS-CoV-2 $\cdot$ Potential cardiotoxicity $\cdot$ Complications

\section{Introduction}

Although there are lacking drugs evident for treating Severe Acute Respiratory Syndrome Coronavirus 2 (SARS-CoV-2), scientists remain attempting to identify those with therapeutic potential [1]. Among the worldwide emerging clinical trials, Solidarity is an international clinical trial searching for an effective Coronavirus disease 2019 (COVID-19) treatment launched by the World Health Organization and its partners

Wei-Ting Chang

cmevecho2@gmail.com

1 Department of Intensive Care Medicine, Chi Mei Medical Center, Tainan, Taiwan

2 Department of Medicine, School of Medicine, College of Medicine, Taipei Medical University, Taipei, Taiwan

3 Institute of Clinical Medicine, College of Medicine, National Cheng Kung University, Tainan, Taiwan

4 Division of Cardiology, Department of Internal Medicine, Chi-Mei Medical Center, 901, Zhonghua Road, Yongkang District,

Tainan, Taiwan

5 Department of Public Health, College of Medicine, National Cheng Kung University, Tainan, Taiwan

6 Department of Biotechnology, Southern Taiwan University of Science and Technology, Tainan, Taiwan
$[2,3]$. The trial intends to rapidly evaluate the potential efficacy of thousands of existing antiviral and anti-inflammatory agents that are not yet approved for treating COVID-19, a process called "repurposing" or "repositioning" [2]. Notably, in case reports, hydroxychloroquine (HCQ) has been regarded as an effective regimen reducing the copy number of SARSCoV-2 [4, 5], but HCQ is also known for its cardiotoxicity [6-8]. In this article, we summarize the updated drugs that are currently regarded as potential anti-SARS-CoV-2 regimens and the documented cardiovascular risks.

\section{Antiviral Drugs}

\section{Remdesivir}

Mechanisms By reducing viral replication and binding to the active site on RNA polymerase of SARS-CoV-2, remdesivir has been viewed as one of the most potentially effective regimens [9]. It has been approved for the treatment of Ebola, respiratory syncytial virus (RSV), Junin virus, Lassa fever virus, Nipah virus, Hendra virus, and the coronaviruses (including MERS and SARS viruses) [9, 10]. According to a case report in the New England Journal of Medicine (NEJM), a patient recovered post remdesivir [11]. However, it may be much more potent if given early in infection. 
Currently, Gilead Sciences is launching several clinical trials to evaluate its effect in patients with moderate or severe COVID-19 compared with those treated with standard care. On April 10, 2020, the company announced it was expanding the enrolled number and changing the end points and subsequently released the preliminary report in the NEJM [12]. Of 53 patients who received at least one dose of remdesivir, 36 (68\%) had improved oxygen support, including 17 of 30 patients $(57 \%)$ receiving mechanical ventilation who were extubated during a median follow-up of 18 days. A total of 25 patients (47\%) were discharged, and 7 (13\%) died. Overall, the mortality was $18 \%$ (6 of 34 ) among patients who received invasive ventilation and $5 \%$ (1 of 19) among those who did not. Although $68 \%$ of the patients demonstrated clinical improvements, the major weakness of this study was a lack of placebo and the non-randomized study design. Further investigation is urgently required.

Drug Interactions As a prodrug, remdesivir is predominantly metabolized by hydrolase activity [10]. It is also a substrate of CYP2C8, CYP2D6, and CYP3A4 in vitro but given its rapid distribution, metabolism, and clearance, coadministration with inhibitors of these CYP isoforms is unlikely to increase remdesivir levels.

Cardiovascular Risks While extensive cardiovascular toxicities and drug interactions have not yet been reported, prior evaluations of this drug during the Ebola outbreak noted that one patient developed hypotension and subsequent cardiac arrest. [13] However, the current evidence indicates that high doses of the drug might be administered without documented cardiotoxicities.

\section{Atazanavir}

Mechanisms Using a deep learning-based drug-target interaction model called molecular transformer-drug target interaction (MT-DTI), atazanavir, an analog of the peptide chain substrate approved for the treatment of HIV, has the potential to prevent the pro-form of SARS-CoV-2 proteins cleaving into the working form. In recent in vitro experiments, atazanavir inhibited SARS-CoV-2 replication and proinflammatory cytokines [14]. Clinical trials have been launched to evaluate its anti-SARS-CoV-2 effect [15].

Drug Interactions As an inhibitor of CYP3A4 and UGT1A1 and a strong inhibitor of OATP1B1, atazanavir may increase the plasma concentrations of other drugs such as proton-pump inhibitors, antacids, and H2-receptor antagonists. Statins such as simvastatin and atorvastatin are also known as CYP $3 A 4$ isoenzyme substrates [16].
Cardiovascular Risks Dose-related asymptomatic prolongation in the PR interval with atazanavir has been observed in clinical studies $[17,18]$. It should be used with caution as prescribed with medicinal products that have the potential to increase the QT interval and/or in patients with preexisting risk factors (bradycardia, long congenital QT, and electrolyte imbalances) [19].

\section{Ritonavir/Lopinavir}

Mechanisms Ritonavir/lopinavir, a combination drug also called Kaletra, was approved in USA in 2000 to treat HIV infection [20]. With the capability to inhibit the protease of $\mathrm{HIV}$, an important enzyme that cleaves a long protein chain into peptides during the assembly of new viruses, ritonavir/ lopinavir may also be able to bind SARS-CoV-2 3C-like proteinase (3CLpro) and consequently suppress its replication [21]. Although ritonavir/lopinavir has been tested in patients diagnosed with SARS or MERS, the results were indeterminate $[22,23]$. In the first randomized and open-label trial conducted in China among 199 COVID-19 patients treated with ritonavir/ lopinavir, no differences were reported compared with the standard care regarding clinical improvements and mortality at 28 days [24]. The percentages of patients with detectable viral RNA at various time points were similar. However, the authors indicated that the overall mortality in this trial $(22.1 \%)$ was substantially higher than the 11 to $14.5 \%$ mortality reported in initial descriptive studies of hospitalized patients infected with SARS-CoV-2 [24]. This implied that the enrolled patents had severe illness or the initiation of ritonavir/lopinavir therapy was too late to reverse the situation. Several ongoing trials continue to investigate the therapeutic effects of ritonavir/ lopinavir on SARS-CoV-2 [15, 24, 25].

Drug Interactions Lopinavir is extensively metabolized by the hepatic cytochrome P450 system, almost exclusively by CYP3A $[20,26]$. It also inhibits drug transporters such as Pgp, BCRP, and OATP1B1 [20]. Thus, ritonavir/lopinavir is prone to increase plasma concentrations of medications primarily metabolized by CYP3A or substrates of these drug transporters. Ritonavir/lopinavir may require dose reductions or avoidance of CYP3A-mediated drugs such as rivaroxaban and apixaban. Ritonavir/lopinavir can also influence the activity of P2Y12 inhibitors through CYP3A4 inhibition, which results in decreased serum concentrations of the active metabolites of clopidogrel and prasugrel and increased serum concentrations of ticagrelor. The VerifyNow P2Y12 assay may be used to monitor the effect of antiplatelet agents [27]. Other agents metabolized by CYP3A are statins. Among them, rosuvastatin undergoes minimal metabolism by CYP450, so no CYP450-based interaction with lopinavir/ritonavir is expected. Otherwise, atorvastatin, pravastatin, and pitavastatin can also be considered at a low starting dose. 
Cardiovascular Risks Ritonavir/lopinavir has been shown to cause QT and PR interval prolongation in some healthy adults $[28,29]$. There were rare reports of second- or third-degree atrioventricular block in patients with underlying structural heart disease and preexisting conduction system abnormalities [30].

\section{Favipiravir}

Mechanisms Due to its competitive inhibition of the RNAdependent RNA polymerase, favipiravir was approved to treat influenza [31]. Although one report showed shorter viral clearance durations and improved chest imaging in patients diagnosed with COVID-19 compared to controls [32], less preclinical support has been established. To date, patients have been recruited to evaluate the efficacy of favipiravir plus interferon- $\alpha$ in China (ChiCTR2000029600) [33]. Based on the anticipated synergistic effect of viral inhibition and immune enhancement, a randomized control trial (THDMSCOVID-19) combining various regimens including protease inhibitors, oseltamivir, favipiravir, and hydroxychloroquine was initiated to test whether the cocktail formula is effective for treating COVID-19 [34].

Drug Interactions Favipiravir is primarily metabolized by aldehyde oxidase and is not involved in CYP isoenzymes [35]. Thus, drug interactions are minimal.

Cardiovascular Risks The QT interval prolongation risk of favipiravir is considered to be low [36].

\section{Ribavirin}

Mechanisms Similar to remdesivir, ribavirin functions as an RNA-dependent RNA polymerase inhibitor and is approved for the treatment of RSV and $\mathrm{HCV}$ [37]. Although ribavirin was recommended for COVID-19 treatment according to Chinese guidelines, it lacks solid evidence [38]. Currently, an open-label randomized controlled trial on lopinavir/ritonavir, ribavirin, and interferon- $\beta 1 \mathrm{~b}$ combination vs lopinavir/ ritonavir alone is ongoing to evaluate the therapeutic effects on COVID-19 [25].

Drug Interactions Ribavirin is metabolized by a reversible phosphorylation pathway or a degradative pathway involving de-ribosylation and amide hydrolysis [39]. It does not inhibit cytochrome P450 enzymes. Therefore, there is minimal potential for P450 enzyme-based interactions. However, case reports showed that ribavirin has variable effects on warfarin dosing [40]. The detailed mechanism has yet to be elucidated.

Cardiovascular Risks No effect on the QT interval was observed in patients receiving ribavirin.

\section{Ivermectin}

Mechanisms Ivermectin causes an influx of $\mathrm{Cl}$ ions through the cell membrane that results in hyperpolarization of ion channels, leading to muscle paralysis [41]. It is approved for the treatment of head lice, scabies, strongyloidiasis, trichuriasis, ascariasis, and lymphatic filariasis [42, 43]. Beyond its anti-parasite effects, ivermectin has also been identified as an inhibitor of interactions between the human HIV integrase protein and the importin $\alpha / \beta 1$ heterodimer $[44,45]$. Notably, studies on SARS-CoV proteins have revealed a potential role of importin $\alpha / \beta 1$ during infection [45]. Nuclear transport of viral proteins is essential for the replication cycle and inhibition of the host's antiviral response [45]. An in vitro study showed that a single ivermectin treatment reduced SARS-CoV-2 by 5000 -fold at $48 \mathrm{~h}$ in cell culture [45]. However, there is a lack of clinical evidence.

Drug Interactions Ivermectin should be considered an inducer of several cytochrome P450 isoenzymes, including CYP1A, 2B, and $3 \mathrm{~A}$ subfamilies [46].

Cardiovascular Risks Tachycardia, orthostatic hypotension, and PR interval prolongation have been documented in case reports $[47,48]$.

\section{Immune-Modulating Drugs}

\section{Hydroxychloroquine (HCQ; Plaquenil)}

Mechanisms Hydroxychloroquine has actions, pharmacokinetics, and metabolism similar to those of chloroquine [49]. As an anti-malarial and anti-autoimmune agent, by sequestering protons in lysosomes, HCQ increases the intracellular $\mathrm{pH}$ in antigen-presenting cells, which is required for virus/cell fusion [50]. It was also shown to suppress the replication of SARS-CoV by interfering with the glycosylation of its cellular receptor ACE2 [51]. Recent in vitro testing revealed its ability to effectively reduce the viral copy number of SARS-CoV-2 [52]. Several small-scale clinical trials demonstrated various degrees of therapeutic effects of HCQ for treating COVID-19associated pneumonia [53, 54]. A small open-label non-randomized clinical trial in France demonstrated a positive effect of HCQ in combination with azithromycin [5]. Upon this finding, although the US FDA issued an Emergency Use Authorization for hydroxychloroquine in treating COVID19, the trial design has been questioned. Most importantly, a high dose of HCQ could cause serious toxicities including cardiomyopathy and fatal arrhythmia $[7,8]$.

Drug Interactions Chloroquine and HCQ undergo CYPmediated metabolism by CYPs 2C8, 3A4, and 2D6 [50]. 
Caution may be required when coadministering comedications metabolized or transported by these pathways such as beta-blockers [55].

Cardiovascular Risks HCQ has an inhibitory effect on the funny current channels $\left(I_{\mathrm{f}}\right)$, a hyperpolarization-activated current ion channel, along with delayed rectifier potassium currents $\left(I_{\mathrm{Kr}}\right)$ and L-type calcium ion currents $\left(I_{\mathrm{CaL}}\right)$ [55]. By blocking these channels, HCQ causes QT prolongation and should be avoided with concomitant QT-prolonging medications such as azithromycin, metabolic derangements, and renal failure [55]. Of note, hydroxychloroquine has a long half-life of 40 days [56]. ECG monitoring is recommended during this therapy. HCQ also has the potential for intermediate to delayed myocardial toxicity [8]. Prolonged exposure (>3 months) or a higher weight-based dose of HCQ may cause restrictive or dilated cardiomyopathy, especially in patients with preexisting cardiac disease or renal failure [8]. On April 11, 2020, the Wall Street Journal reported that since March 27, the Pharmacovigilance Center in Nice, France, received up to 54 cases developing cardiovascular complications post-hydroxychloroquine use for the treatment of COVID-19 [57].

\section{Tocilizumab}

Mechanisms The rapid development of ARDS in patients diagnosed with COVID-19 may not be primarily due to SARS-CoV-2 per se but the cytokine storm [58]. Interleukin (IL)- 6 is one of the most important proinflammatory cytokines [58]. Hence, specific blockade of the IL-6-regulated signaling pathways represents a promising approach to attenuate inflammation-associated damage [59]. Tocilizumab is an antihuman interleukin 6 (IL-6) receptor monoclonal antibody approved for the treatment of rheumatoid arthritis and systemic juvenile idiopathic arthritis $[60,61]$. In a recently published study of 15 patients with COVID-19, tocilizumab combined with methylprednisolone ameliorated increased CRP and IL-6, but the result was insufficient to support its therapeutic effects [62]. Upon the recently launched randomized, double-blind, placebo-controlled phase III clinical trial called COVACTA, the safety and efficacy of intravenous tocilizumab in hospitalized adult patients with severe COVID-19 pneumonia will be compared with placebo in addition to the standard of care [63].

Drug Interactions Tocilizumab has no inhibitory effects on cytochromes. However, tocilizumab reverses IL-6 induced suppression of cytochromes and the elevation of IL- 6 during inflammation has been shown to inhibit CYP3A4, CYP2C19, CYP2C9, and CYP1A2 expression, resulting in higher exposure of substrate drugs [64].
Cardiovascular Risks No clinically significant effect on QT prolongation was observed in healthy subjects at therapeutic doses. Some patients taking tocilizumab experienced rapid increases in blood pressure and low-density lipoprotein cholesterol [65]. However, according to the findings of the ENTRACTE study that compared the cardiovascular safety in patients with rheumatoid arthritis receiving either tocilizumab or etanercept [66], there were no significant increases in stroke, heart attack, heart failure hospitalization, or cardiac death.

\section{Interferon- $\beta$}

Mechanisms Type 1 interferons (IFN-I) play a major role in antiviral immunity [67]. Because of their immunomodulatory properties, IFN- $\beta$ is used to treat many diseases, including multiple sclerosis [68]. When used alone or in combination with other drugs, IFN-I exerts a broad-spectrum antiviral effect against HCV, RSV [69]. This study showed that IFN-I can be used as a prophylaxis against SARS-CoV-2, which was confirmed by the in vitro efficacy of interferon pretreatment against the virus [70], while the replication of MERS-CoV [71] and SARS [72] was reported to be indifferent to IFN-I prophylaxis. Trials are now focusing on the safety and efficacy for treating COVID-19 pneumonia [73]. SOLIDARITY will also have an arm that combines the two antivirals with interferon-beta, a molecule involved in regulating inflammation in the body that has also shown an effect in marmosets infected with MERS [3].

Drug Interactions It reduces the activity of hepatic cytochrome P450-dependent enzymes [74].

Cardiovascular Risks No clinically significant effects on QTc prolongation have been observed. Only rare case reports showed premature ventricular captures and atrioventricular block [75].

\section{Fingolimod (FTY-720)}

Mechanisms Fingolimod is an oral immunomodulating agent that is primarily used to treat refractory multiple sclerosis [76]. By structurally resembling the lipid sphingosine-1-phosphate (S1P), fingolimod can act as a highly potent functional antagonist of S1P1 receptors in the lymph node T cells [76]. Similar to the immunomodulatory properties of IFN-I, fingolimod is regarded as a method of treating the SARS-CoV-2 triggered overactivation of immune responses [77]. A non-randomized and open-label study is preparing to evaluate the efficacy of fingolimod for treating COVID-19 [78].

Drug Interactions Fingolimod is primarily metabolized by CYP4F2 [79]. Since few drugs are metabolized by CYP4F2, 


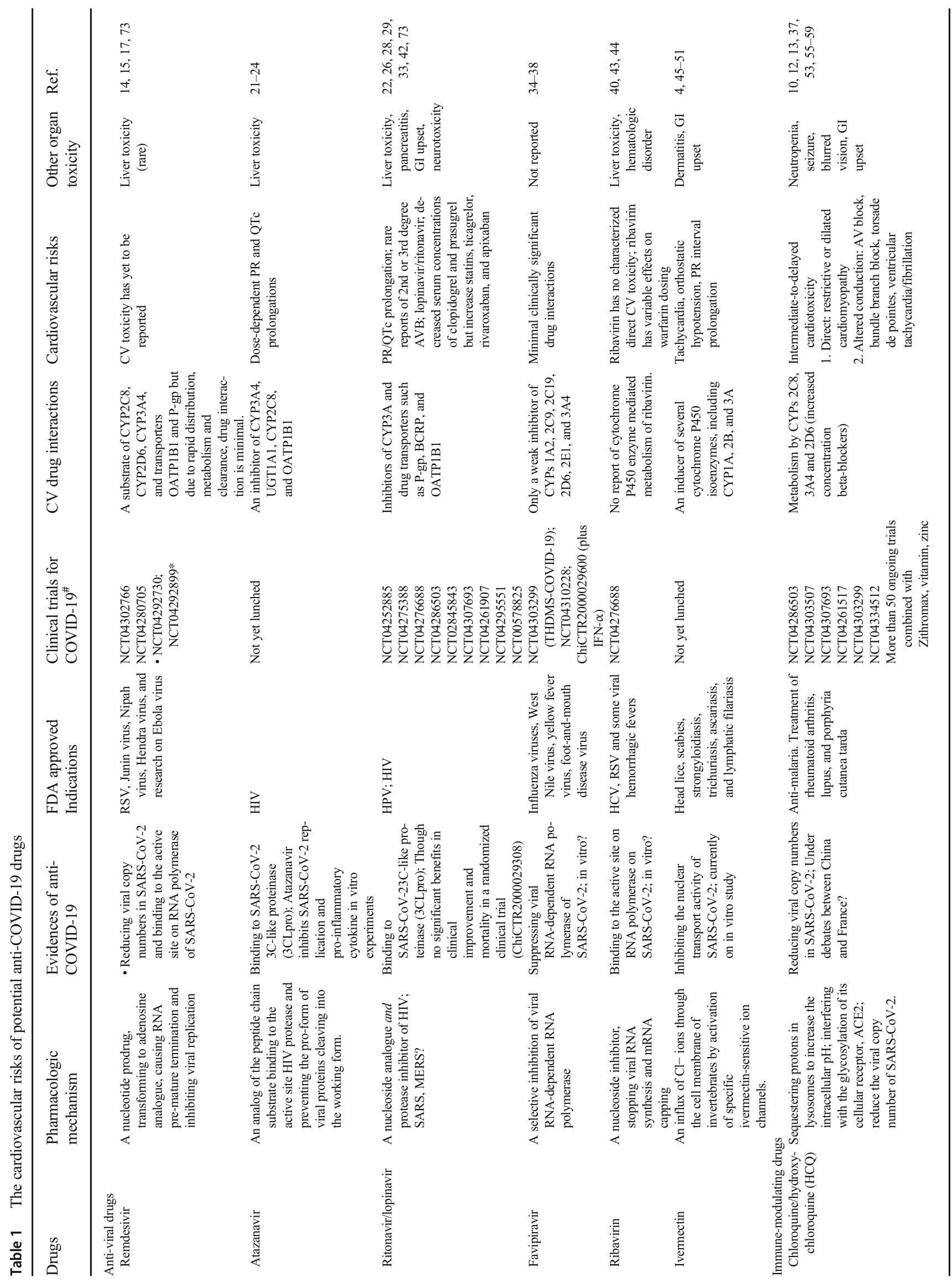




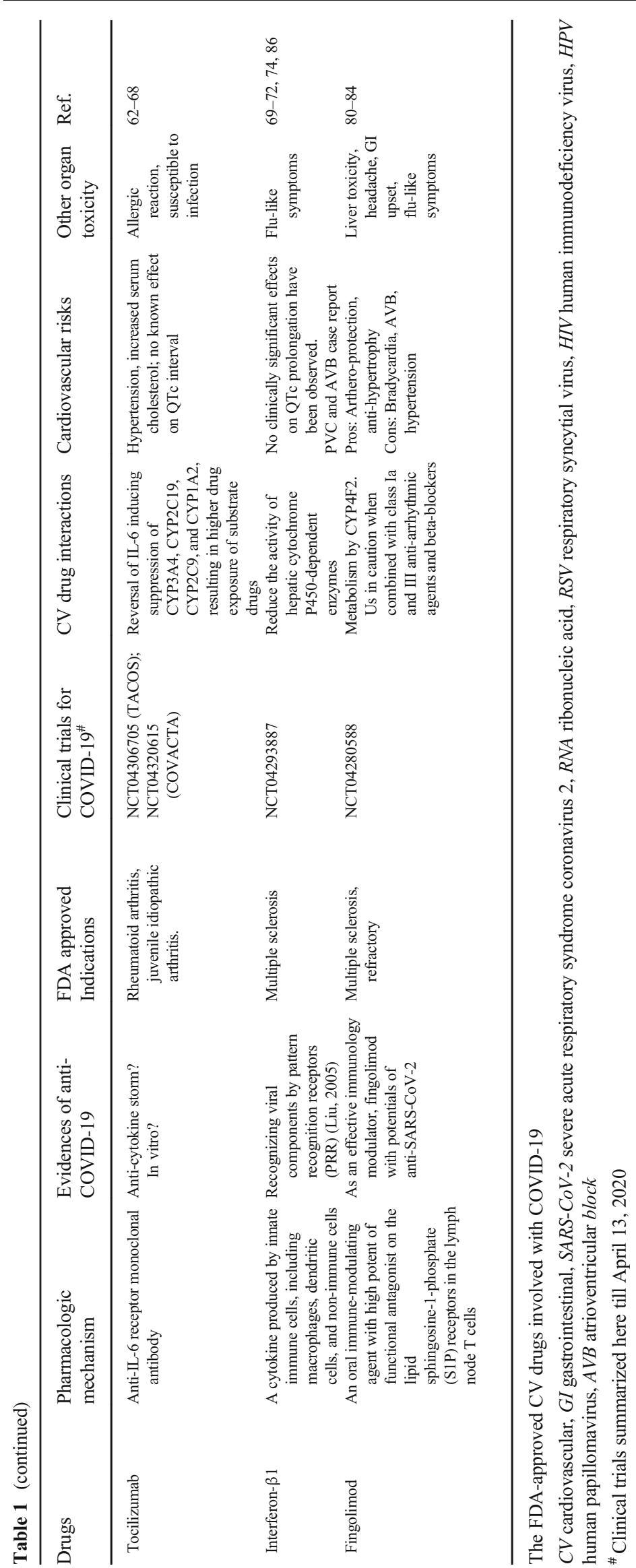




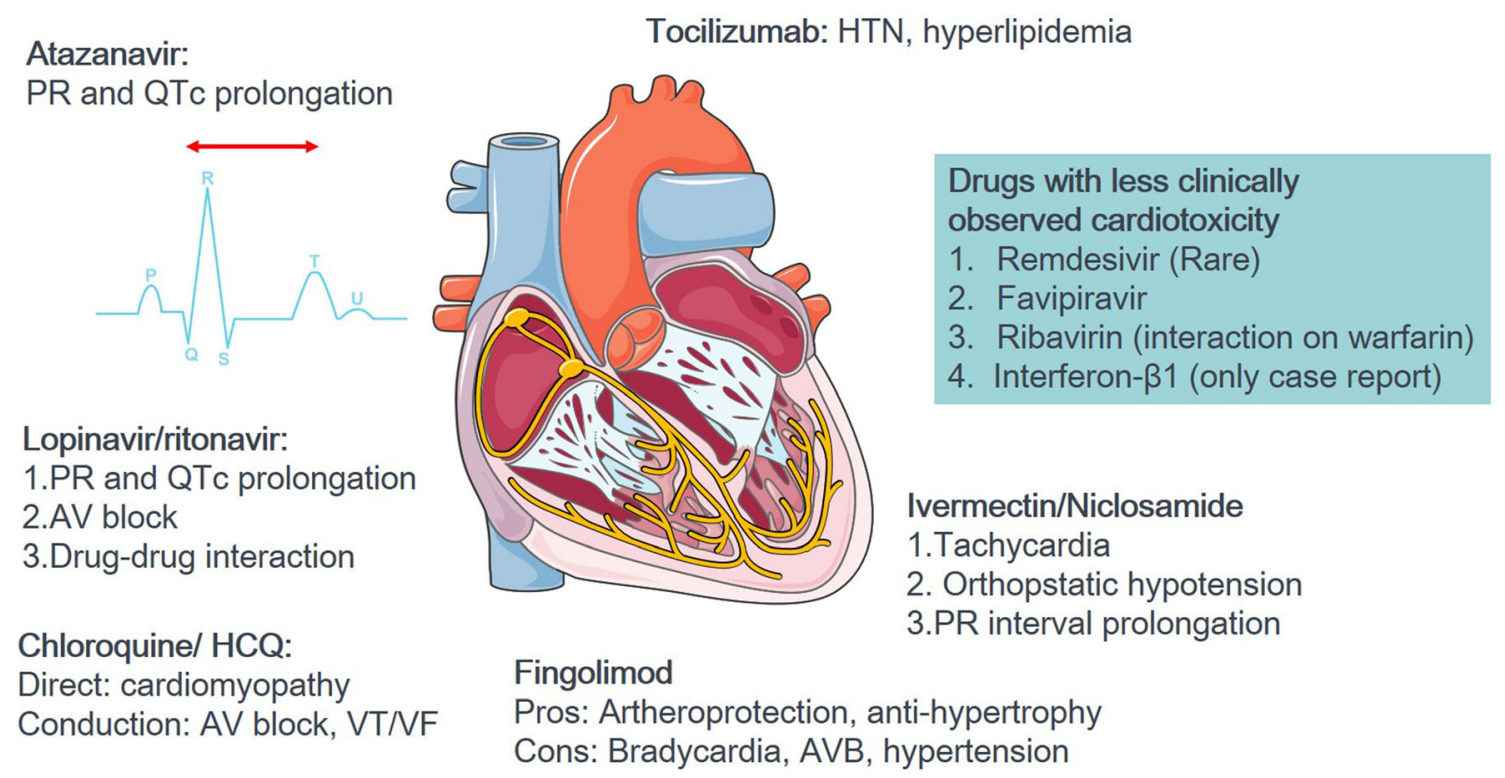

Fig. 1 The illustration of cardiovascular concerns of potential anti-COVID-19 drugs

fingolimod is expected to have a relatively low potential for drug-drug interactions. However, it should be used with caution when combined with class Ia and III anti-arrhythmic agents and beta-blockers [80]. CYP4F2 genotypes were observed contributing to both warfarin clearance and sensitivity differences [79].

Cardiovascular Risks Given that S1P is crucially involved in vascular barrier function, coagulation, vascular homeostasis, angiogenesis, and atherosclerosis, Fingolimod has been reported to induce bradyarrhythmia, atrioventricular block, and blood pressure through increasing the vascular tone [81, 82]. Regarding fingolimod-induced intracellular calcium release and its consequent contractile effects on smooth muscle cells, it may cause retinal arterial vasospasm and retinal vein occlusion [76, 81]. Conversely, upon its atheroprotective effects, fingolimod diminishes atherosclerosis plaque volume and macrophage and collagen content in vivo [83]. In another perspective, through S1P cascade to p-21 activated kinase (Pak1), a pivotal regulator of channel activity and contractility, fingolimod resists load stress-induced murine hypertrophic remodeling without deterioration of cardiac function [83].

\section{Conclusions}

Collectively, in this review we summarized the current state of knowledge on FDA-approved drugs with potentials for treating SARS-CoV-2 and the COVID-19 pandemic. Most importantly, given that patients affected by this disease commonly have cardiovascular comorbidities, a careful evaluation of the possible cardiovascular complications of these drugs is crucial. Table 1 summarizes the updated drugs with anti-
SARS-CoV-2 potential, pharmacologic mechanisms, preliminary results of studies, ongoing clinical trials, drug metabolism, and the possible cardiovascular complications. Most of the drugs are based on repurposing therapeutic agents previously designed for other applications. These agents can be divided into two categories, including those with antiviral or immune-modulating effects. We reviewed several drugs with updated information until the middle April 2020. Figure 1 shows that among the aforementioned drugs, remdesivir, favipiravir, ribavirin, and interferon- $\beta 1$ have been less reported with cardiovascular complications. We believe that this review provides additional cardiovascular concerns along with the aggressive exploration of candidate drugs with antiSARS-CoV-2 potential.

Funding Information This work was supported by Chi-Mei Medical Center.

\section{Compliance with Ethical Standards}

Conflict of Interest The authors declare that they have no conflict of interest.

\section{References}

1. Zhou Y, Hou Y, Shen J, Huang Y, Martin W, Cheng F. Networkbased drug repurposing for novel coronavirus 2019-nCoV/SARSCoV-2. Cell Discov. 2020;6:14.

2. Qian X, Ren R, Wang Y, Guo Y, Fang J, Wu ZD, et al. Fighting against the common enemy of COVID-19: a practice of building a community with a shared future for mankind. Infect Dis Poverty. 2020;9(1):34.

3. Organization WH. "Solidarity" clinical trial for COVID-19 treatments. 2020. 
4. Gautret P, Lagier JC, Parola P, Hoang VT, Meddeb L, Mailhe M, et al. Hydroxychloroquine and azithromycin as a treatment of COVID-19: results of an open-label non-randomized clinical trial. Int J Antimicrob Agents. 2020:105949.

5. Gautret P, Lagier J-C, Parola P, Meddeb L, Mailhe M, Doudier B, et al. Hydroxychloroquine and azithromycin as a treatment of COVID-19: results of an open-label non-randomized clinical trial. Int J Antimicrob Agents 2020:105949.

6. Driggin E, Madhavan MV, Bikdeli B, Chuich T, Laracy J, BondiZoccai G, et al. Cardiovascular considerations for patients, health care workers, and health systems during the coronavirus disease 2019 (COVID-19) pandemic. J Am Coll Cardiol. 2020;75:235271.

7. Chen C-Y, Wang F-L, Lin C-C. Chronic hydroxychloroquine use associated with QT prolongation and refractory ventricular arrhythmia. Clin Toxicol. 2006;44(2):173-5.

8. Joyce E, Fabre A, Mahon N. Hydroxychloroquine cardiotoxicity presenting as a rapidly evolving biventricular cardiomyopathy: key diagnostic features and literature review. Eur Heart J Acute Cardiovasc Care. 2013;2(1):77-83.

9. Gordon CJ, Tchesnokov EP, Feng JY, Porter DP, Gotte M. The antiviral compound remdesivir potently inhibits RNA-dependent RNA polymerase from Middle East respiratory syndrome coronavirus. J Biol Chem. 2020;295(15):4773-9.

10. Tchesnokov EP, Feng JY, Porter DP, Gotte M. Mechanism of inhibition of ebola virus RNA-dependent RNA polymerase by remdesivir. Viruses. 2019;11(4):326.

11. Holshue ML, DeBolt C, Lindquist S, Lofy KH, Wiesman J, Bruce $\mathrm{H}$, et al. First case of 2019 novel coronavirus in the United States. N Engl J Med. 2020;382(10):929-36.

12. Grein J, Ohmagari N, Shin D, Diaz G, Asperges E, Castagna A, et al. Compassionate use of remdesivir for patients with severe Covid-19. N Engl J Med. 2020;382:2327-36.

13. Lucey DR. New treatments for Ebola virus disease. BMJ. 2019;366:15371.

14. Beck BR, Shin B, Choi Y, Park S, Kang K. Predicting commercially available antiviral drugs that may act on the novel coronavirus (2019-nCoV), Wuhan, China through a drug-target interaction deep learning model. bioRxiv. 2020.

15. Atazanavir/Ritonavir Maintenance Therapy. NCT00084019. 2020.

16. Tafatatha T, Taegtmeyer M, Ngwira B, Phiri A, Kondowe M, Piston W, et al. Human immunodeficiency virus, antiretroviral therapy and markers of lymphatic filariasis infection: a cross-sectional study in rural Northern Malawi. PLoS Negl Trop Dis. 2015;9(6): e0003825.

17. Busti AJ, Tsikouris JP, Peeters MJ, Das SR, Canham RM, Abdullah $\mathrm{SM}$, et al. A prospective evaluation of the effect of atazanavir on the QTc interval and QTc dispersion in HIV-positive patients. HIV Med. 2006;7(5):317-22.

18. Gallagher DP, Kieran J, Sheehan G, Lambert J, Mahon N, Mallon PW. Ritonavir-boosted atazanavir, methadone, and ventricular tachycardia: 2 case reports. Clin Infect Dis. 2008;47(3):e36-8.

19. Ly T, Ruiz ME. Prolonged QT interval and torsades de pointes associated with atazanavir therapy. Clin Infect Dis. 2007;44(6): e67-8.

20. Feng H-P, Caro L, Fandozzi C, Chu X, Guo Z, Talaty J, et al. Pharmacokinetic interactions between the hepatitis $C$ virus inhibitors elbasvir and grazoprevir and HIV protease inhibitors ritonavir, atazanavir, lopinavir, and darunavir in healthy volunteers. Antimicrob Agents Chemother. 2019;63(4):e02142-18.

21. Chen YW, Yiu CB, Wong KY. Prediction of the SARS-CoV-2 (2019-nCoV) 3C-like protease (3CL (pro)) structure: virtual screening reveals velpatasvir, ledipasvir, and other drug repurposing candidates. F1000Res. 2020;9:-129.
22. Chu CM, Cheng VC, Hung IF, Wong MM, Chan KH, Chan KS, et al. Role of lopinavir/ritonavir in the treatment of SARS: initial virological and clinical findings. Thorax. 2004;59(3):252-6.

23. Yao TT, Qian JD, Zhu WY, Wang Y, Wang GQ. A systematic review of lopinavir therapy for SARS coronavirus and MERS coronavirus-a possible reference for coronavirus disease-19 treatment option. J Med Virol. 2020;92:556-63.

24. Cao B, Wang Y, Wen D, Liu W, Wang J, Fan G, et al. A trial of lopinavir-ritonavir in adults hospitalized with severe Covid-19. N Engl J Med. 2020;382:1787-99.

25. Lopinavir/Ritonavir, Ribavirin and IFN-beta Combination for nCoV Treatment. 2020;NCT04276688.

26. van der Lee M, Sankatsing R, Schippers E, Vogel M, Fatkenheuer $\mathrm{G}$, van der Ven A, et al. Pharmacokinetics and pharmacodynamics of combined use of lopinavir/ritonavir and rosuvastatin in HIVinfected patients. Antivir Ther. 2007;12(7):1127-32.

27. van Werkum JW, Harmsze AM, Elsenberg EH, Bouman HJ, ten Berg JM, Hackeng CM. The use of the VerifyNow system to monitor antiplatelet therapy: a review of the current evidence. Platelets. 2008;19(7):479-88.

28. Soliman EZ, Lundgren JD, Roediger MP, Duprez DA, Temesgen Z, Bickel M, et al. Boosted protease inhibitors and the electrocardiographic measures of QT and PR durations. AIDS. 2011;25(3): 367-77.

29. Charbit B, Rosier A, Bollens D, Boccara F, Boelle PY, Koubaa A, et al. Relationship between HIV protease inhibitors and QTc interval duration in HIV-infected patients: a cross-sectional study. Br J Clin Pharmacol. 2009;67(1):76-82.

30. Puech R, Gagnieu MC, Planus C, Charpiat B, Boibieux A, Ferry T, et al. Extreme bradycardia due to multiple drug-drug interactions in a patient with HIV post-exposure prophylaxis containing lopinavirritonavir. Br J Clin Pharmacol. 2011;71(4):621-3.

31. Furuta Y, Komeno T, Nakamura T. Favipiravir (T-705), a broad spectrum inhibitor of viral RNA polymerase. Proc Jpn Acad Ser B Phys Biol Sci. 2017;93(7):449-63.

32. Qingxian Caia MY, Liu D, et al. Experimental treatment with favipiravir for COVID-19: an open-label control study. Engineering. 2020.

33. Registry CCT. Clinical study for safety and efficacy of Favipiravir in the treatment of novel coronavirus pneumonia (COVID-19). 2020;ChiCTR2000029600.

34. Various Combination of Protease Inhibitors, Oseltamivir, Favipiravir, and Hydroxychloroquine for Treatment of COVID19 : A Randomized Control Trial (THDMS-COVID-19). 2020;NCT04303299.

35. Gowen BB, Sefing EJ, Westover JB, Smee DF, Hagloch J, Furuta $\mathrm{Y}$, et al. Alterations in favipiravir (T-705) pharmacokinetics and biodistribution in a hamster model of viral hemorrhagic fever. Antivir Res. 2015;121:132-7.

36. Chinello P, Petrosillo N, Pittalis S, Biava G, Ippolito G, Nicastri E, et al. QTc interval prolongation during favipiravir therapy in an Ebolavirus-infected patient. PLoS Negl Trop Dis. 2017;11(12): e0006034.

37. Thomas E, Ghany MG, Liang TJ. The application and mechanism of action of ribavirin in therapy of hepatitis C. Antivir Chem Chemother. 2012;23(1):1-12.

38. Jin YH, Cai L, Cheng ZS, Cheng H, Deng T, Fan YP, et al. A rapid advice guideline for the diagnosis and treatment of 2019 novel coronavirus (2019-nCoV) infected pneumonia (standard version). Mil Med Res. 2020;7(1):4.

39. Goodarzi N, Barazesh Morgani A, Abrahamsson B, Cristofoletti R, Groot DW, Langguth P, et al. Biowaiver monographs for immediate release solid oral dosage forms: ribavirin. J Pharm Sci. 2016;105(4):1362-9.

40. Schulman S. Inhibition of warfarin activity by ribavirin. Ann Pharmacother. 2002;36(1):72-4. 
41. Atif M, Estrada-Mondragon A, Nguyen B, Lynch JW, Keramidas A. Effects of glutamate and ivermectin on single glutamate-gated chloride channels of the parasitic nematode $H$. contortus. PLoS Pathog. 2017;13(10):e1006663.

42. Coscione S, Esau T, Kekeubata E, Diau J, Asugeni R, MacLaren D, et al. Impact of ivermectin administered for scabies treatment on the prevalence of head lice in Atoifi Solomon Islands. PLoS Negl Trop Dis. 2018;12(9):e0006825.

43. Beach MJ, Streit TG, Addiss DG, Prospere R, Roberts JM, Lammie PJ. Assessment of combined ivermectin and albendazole for treatment of intestinal helminth and Wuchereria bancrofti infections in Haitian schoolchildren. Am J Trop Med Hyg. 1999;60(3):479-86.

44. Wagstaff KM, Sivakumaran H, Heaton SM, Harrich D, Jans DA. Ivermectin is a specific inhibitor of importin alpha/beta-mediated nuclear import able to inhibit replication of HIV-1 and dengue virus. Biochem J. 2012;443(3):851-6.

45. Caly L, Druce JD, Catton MG, Jans DA, Wagstaff KM. The FDAapproved drug ivermectin inhibits the replication of SARS-CoV-2 in vitro. Antivir Res. 2020;178:104787.

46. Skalova L, Szotakova B, Machala M, Neca J, Soucek P, Havlasova $\mathrm{J}$, et al. Effect of ivermectin on activities of cytochrome P450 isoenzymes in mouflon (Ovis musimon) and fallow deer (Dama dama). Chem Biol Interact. 2001;137(2):155-67.

47. Sparsa A, Bonnetblanc JM, Peyrot I, Loustaud-Ratti V, Vidal E, Bedane C. Systemic adverse reactions with ivermectin treatment of scabies. Ann Dermatol Venereol. 2006;133(10):784-7.

48. Goa KL, McTavish D, Clissold SP. Ivermectin. A review of its antifilarial activity, pharmacokinetic properties and clinical efficacy in onchocerciasis. Drugs. 1991;42(4):640-58.

49. Manic G, Obrist F, Kroemer G, Vitale I, Galluzzi L. Chloroquine and hydroxychloroquine for cancer therapy. Mol Cell Oncol. 2014;1(1):e29911.

50. Schrezenmeier E, Dorner T. Mechanisms of action of hydroxychloroquine and chloroquine: implications for rheumatology. Nat Rev Rheumatol. 2020;16(3):155-66.

51. Vincent MJ, Bergeron E, Benjannet S, Erickson BR, Rollin PE, Ksiazek TG, et al. Chloroquine is a potent inhibitor of SARS coronavirus infection and spread. Virol J. 2005;2:69.

52. Liu J, Cao R, Xu M, Wang X, Zhang H, Hu H, et al. Hydroxychloroquine, a less toxic derivative of chloroquine, is effective in inhibiting SARS-CoV-2 infection in vitro. Cell Discov. 2020;6:16.

53. Sahraei Z, Shabani M, Shokouhi S, Saffaei A. Aminoquinolines against coronavirus disease 2019 (COVID-19): chloroquine or hydroxychloroquine. Int J Antimicrob Agents. 2020;105945: 105945.

54. Colson P, Rolain JM, Lagier JC, Brouqui P, Raoult D. Chloroquine and hydroxychloroquine as available weapons to fight COVID-19. Int J Antimicrob Agents. 2020;55:105932.

55. Capel RA, Herring N, Kalla M, Yavari A, Mirams GR, Douglas G, et al. Hydroxychloroquine reduces heart rate by modulating the hyperpolarization-activated current If: Novel electrophysiological insights and therapeutic potential. Heart Rhythm. 2015;12(10): 2186-94.

56. Tett SE, Cutler DJ, Day RO, Brown KF. Bioavailability of hydroxychloroquine tablets in healthy volunteers. Br J Clin Pharmacol. 1989;27(6):771-9.

57. Journal TWS. French doctor leads charge for treating coronavirus with antimalarial drug. April, 11, 2020.

58. Pedersen SF, Ho Y-C. SARS-CoV-2: a storm is raging. J Clin Invest. 2020;130:2202-5.

59. Jones SA, Jenkins BJ. Recent insights into targeting the IL-6 cytokine family in inflammatory diseases and cancer. Nat Rev Immunol. 2018;18(12):773-89.
60. Alten R. Tocilizumab: a novel humanized anti-interleukin 6 receptor antibody for the treatment of patients with rheumatoid arthritis. Ther Adv Musculoskelet Dis. 2011;3(3):133-49.

61. Yokota S, Itoh Y, Morio T, Origasa H, Sumitomo N, Tomobe M, et al. Tocilizumab in systemic juvenile idiopathic arthritis in a real-world clinical setting: results from 1 year of postmarketing surveillance follow-up of 417 patients in Japan. Ann Rheum Dis. 2016;75(9): $1654-60$.

62. Luo P, Liu Y, Qiu L, Liu X, Liu D, Li J. Tocilizumab treatment in COVID-19: a single center experience. J Med Virol. 2020.

63. FDA Approves Phase III Clinical Trial of Tocilizumab for COVID19 Pneumonia. March 26, 2020.

64. Schmitt C, Kuhn B, Zhang X, Kivitz AJ, Grange S. Disease-drugdrug interaction involving tocilizumab and simvastatin in patients with rheumatoid arthritis. Clin Pharmacol Ther. 2011;89(5):73540.

65. Cacciapaglia F, Anelli MG, Rinaldi A, Fornaro M, Lopalco G, Scioscia C, et al. Lipids and atherogenic indices fluctuation in rheumatoid arthritis patients on long-term tocilizumab treatment. Mediat Inflamm. 2018;2018:2453265.

66. Giles JT, Sattar N, Gabriel S, Ridker PM, Gay S, Warne C, et al. Cardiovascular safety of tocilizumab versus etanercept in rheumatoid arthritis: a randomized controlled trial. Arthritis Rheum. 2020;72(1):31-40.

67. Murira A, Lamarre A. Type-I interferon responses: from friend to foe in the battle against chronic viral infection. Front Immunol. 2016;7:609.

68. Panitch HS, Bever CT Jr. Clinical trials of interferons in multiple sclerosis. What have we learned? J Neuroimmunol. 1993;46(1-2): $155-64$

69. Hijano DR, Vu LD, Kauvar LM, Tripp RA, Polack FP, Cormier SA. Role of type I interferon (IFN) in the respiratory syncytial virus (RSV) immune response and disease severity. Front Immunol. 2019;10:566.

70. Sallard E, Lescure FX, Yazdanpanah Y, Mentre F, Peiffer-Smadja $\mathrm{N}$, Committee CDFS. Type 1 interferons as a potential treatment against COVID-19. Antivir Res. 2020;178:104791.

71. Sheahan TP, Sims AC, Leist SR, Schafer A, Won J, Brown AJ, et al. Comparative therapeutic efficacy of remdesivir and combination lopinavir, ritonavir, and interferon beta against MERS-CoV. Nat Commun. 2020;11(1):222.

72. Kindler E, Thiel V, Weber F. Interaction of SARS and MERS coronaviruses with the antiviral interferon response. Adv Virus Res. 2016;96:219-43.

73. Efficacy and Safety of IFN- $\alpha 2 \beta$ in the Treatment of Novel Coronavirus Patients. NCT04293887.

74. Tapner M, Liddle C, Goodwin B, George J, Farrell GC. Interferon gamma down-regulates cytochrome $\mathrm{P} 4503 \mathrm{~A}$ genes in primary cultures of well-differentiated rat hepatocytes. Hepatology. 1996;24(2):367-73.

75. Teragawa H, Hondo T, Amano H, Hino F, Ohbayashi M. Adverse effects of interferon on the cardiovascular system in patients with chronic hepatitis C. Jpn Heart J. 1996;37(6):905-15.

76. Chun J, Brinkmann V. A mechanistically novel, first oral therapy for multiple sclerosis: the development of fingolimod (FTY720, Gilenya). Discov Med. 2011;12(64):213-28.

77. Rosa SGV, Santos WC. Clinical trials on drug repositioning for COVID-19 treatment. Rev Panam Salud Publica. 2020;44:e40.

78. Fingolimod in COVID-19. 2020;NCT04280588.

79. David OJ, Kovarik JM, Schmouder RL. Clinical pharmacokinetics of fingolimod. Clin Pharmacokinet. 2012;51(1):15-28.

80. Jain N, Bhatti MT. Fingolimod-associated macular edema: incidence, detection, and management. Neurology. 2012;78(9):67280 .

81. Behjati M, Etemadifar M, Abdar EM. Cardiovascular effects of fingolimod: a review article. Iran J Neurol. 2014;13(3):119-26. 
82. Racca V, Rovaris M, Vaini E, Cavarretta R, Ferratini M, Toccafondi A, et al. 6-Month effects of fingolimod on indexes of cardiovascular autonomic control in multiple sclerosis. J Am Coll Cardiol. 2016;68(18):2027-9.

83. Egom EE, Mohamed TM, Mamas MA, Shi Y, Liu W, Chirico D, et al. Activation of Pak1/Akt/eNOS signaling following sphingosine-1-phosphate release as part of a mechanism protecting cardiomyocytes against ischemic cell injury. Am J Physiol Heart Circ Physiol. 2011;301(4):H1487-95.

Publisher's Note Springer Nature remains neutral with regard to jurisdictional claims in published maps and institutional affiliations. 